Vol. 4, Special Issue 2, January 2017

\title{
Industrial Monitoring using Raspberry Pi Technology
}

\author{
Raut Poonam ${ }^{1}$, Kumbhar Sonali ${ }^{2}$ \\ Student E\&TC Department, Dr. Daulatrao Aher College of Engineering, Karad, India ${ }^{1}$ \\ Assistant Prof. E\&TC Department, Dr. Daulatrao Aher College of Engineering, Karad, India ${ }^{2}$
}

\begin{abstract}
This paper represents implementation of industrial monitoring using raspberry pi technology. It can control various industrial parameters like temperature, pressure, flow, proximity. Operating system of Raspberry pi is Rasp Bain os. Raspberry pi is single board computer it has small size like credit card. It is low power consuming . The Raspberry pi system operate on window or Linux operating system.
\end{abstract}

Keywords: Raspberry pi, wireless sensor, Industrial monitoring parameter temperature, pressure, flow and proximity.

\section{INTRODUCTION}

Real time system is continuous and reliable system and also system present low cost and low power consuming. Now days the wireless networks are standardized for industrial application. This system is a quick and accurate power system monitoring. Now a days the accident in industry quickly therefore the wireless system play important role in industry.

Single person can operate whole work. In industry the wired communication are not used because the sometime wire get damaged and data can be transmitted to required distance so wireless communication are use or play important role in industry. The real time data are more use for future analysis. Wireless system is one of the fastest technologies in process automation area. Human safety is important in hazardous area at that time there are no person is present on that area for monitoring it causes accident. For that reason we use sensor to alert the workers. Temperature, humidity, flow and proximity are measure parameter. This parameter is commonly used hospital, milk, medicine Production Company and chemical industry.

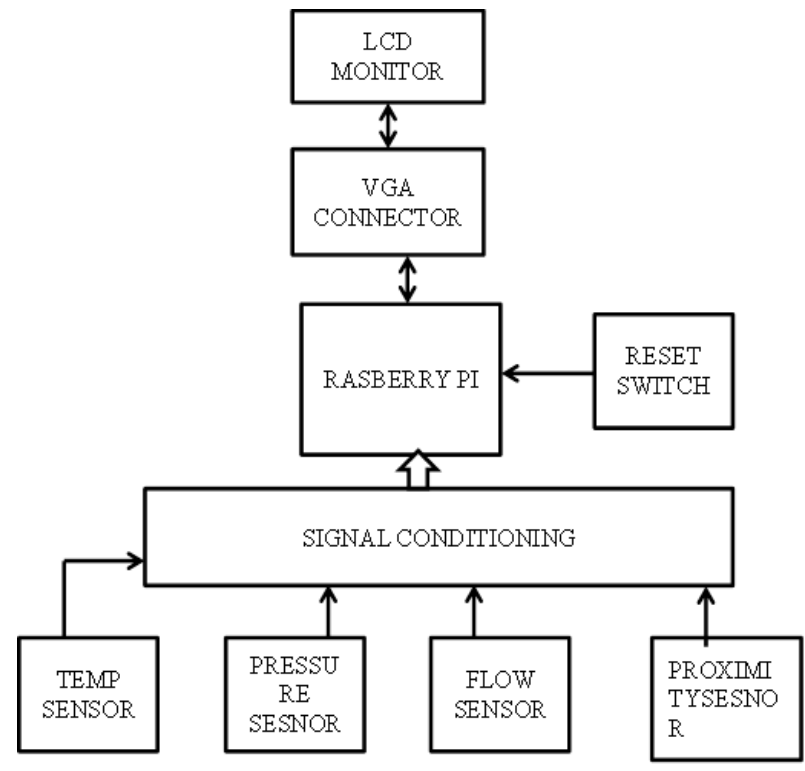

Fig 1. Functional Block Diagram

\section{III.HARDWARE DESCRIPTIONS}

\section{FUNCTIONAL DESCRIPTION}

In our project monitoring of various industrial parameters like temperature, pressure, flow and proximity with real time computing system and monitoring system access anywhere and anytime when internet inbuilt from fig four sensors are connected to the signal conditioning unit .

The unit convert ac signal to de signal signal conditioning unit and also reset switch connect to the Raspberry pi .Reset switch is used for restart the program. Raspberry pi is nothing but decision making device. Raspberry pi is 16 bit device. VGA connector placed between LCD Monitor and Raspberry pi module .LCD monitor are used to display output.

\section{A. Raspberry PI Module}

Raspberry pi is low power consuming device. It is decision making device developed model B in February 2016 in United Kingdom. The price between 20 and 35 US $\$$. This system based on real time operating system (RTOS). The RTOS execute many tasks at any time (Multitasking). It operates 2.4GHZ frequency. All programs are done through python language. Operating system is Rasp Bain and it is based on Linux type operating system. Programming is done by to interfacing 1) Hardware interfacing 2) Display interfacing. It includes general purpose input output (GPIO). Standard USB keyboard are work with Raspberry pi. Credit card sized Raspberry pi module is plugged into a computer monitor or TV and uses a standard keyboard and mouse. [1] [4] [6] 
IARJSET

Vol. 4, Special Issue 2, January 2017

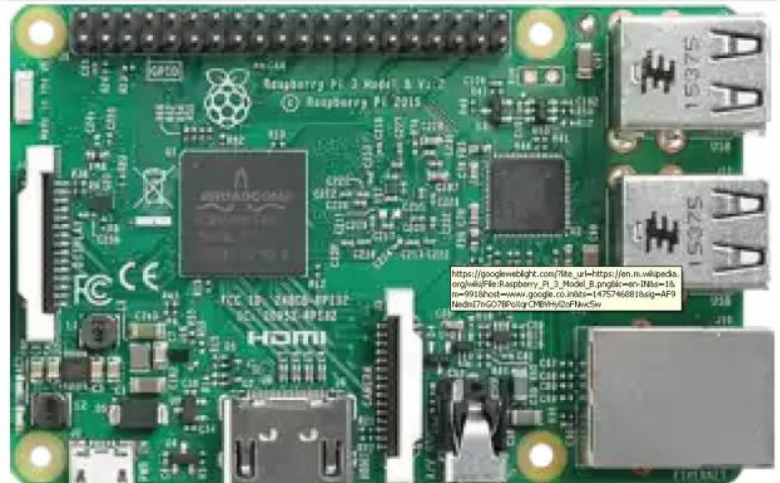

Fig 2. RaspberryPi

B. Temperature Sensor (LM35)

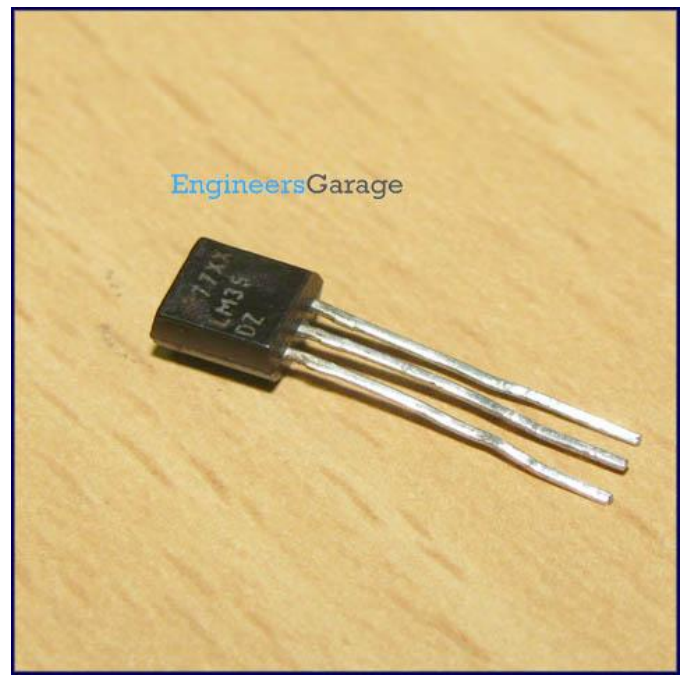

Fig 3. LM35 Temperature Sensor

Boiling steam is used in temperature sensor. Temperature converts to voltage level using 3 pins such as GND, Voltage source and Output voltage. If temperature increases then voltage will be increase. It senses any level of temperature. The LM35 Temperature sensors are integrated circuit device. The temperature sensor measured in Kelvin. The output voltage of an LM35 temperature sensor is linearly proportional to the centigrade temperature. The LM35 is beneficial than linear temperature sensor. The device used single power supply.[7]

Sensitivity: -30 to +150

Voltage: $5 \mathrm{~V}$

Power: $120 \mathrm{MW}$

\section{BMP085 Flow Sensor}

The Pressure of water is measured using flow sensor. It is capable of measuring (-10 to120) Pascal. Flow sensor consists of plastic valve body, hall-effect sensor, water rotor. When water flows through the rotor, rotor rolls. Its speed change with different rate of flow. The output of hall -effect sensor corresponding pulse signal.[7]

Range: -10 to 120 Pascal
Voltage: $5 \mathrm{~V}$

Power: 120MW

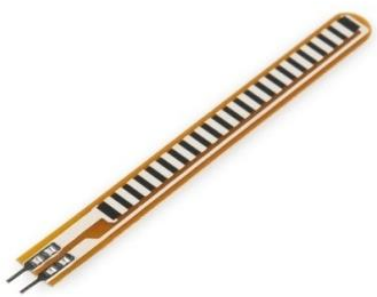

Fig 4. Flow Sensor

D. Proximity Sensor (LMP91300)

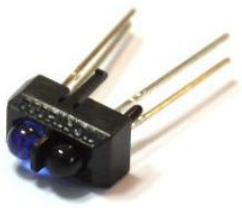

Fig 5. Proximity Sensor

Proximity sensor is a sensor able to detect the presence of nearby objects without any physical contact. Different proximity sensors target demand different sensors. For example, a capacitive or photo elective sensor. LMP91300 is complete analogy front end use in industrial inductive proximity sensor. The internal voltage regulator the device operates with supply from $6.5 \mathrm{~V}$ to $40 \mathrm{~V}$. The output can be deriving external transistor either NPN or PNP mode. They provide programmable temperature compensation and programmable threshold. Connector placed between LCD Monitor and Raspberry pi module .LCD monitor are used to display [2 ] [7].

\section{IV.SOFTWARE DESCRIPTION}

Software requirement as follows:

A. Linux Operating System

Operating system is Rasp Bain and it is based on Linux operating system. Also used for multiprogramming, multitasking. Source model used is an open source. Linux is a UNIX like computer operating system assembles under the model of free and open source software development and distribution. They first released 17 September 1991 by Linux troves. It includes window technique. [1] [7]

\section{B. Python language}

Python is programming script language. Programming is done in hardware and display interface. Python is used as general purpose language. In this language design philosophy and its syntax allows programmer to express concept in fewer lines of codes like C++ and java. Python is widely used high level and dynamic programming language. The language provides constructs intended to enable writing clear programs on both small and large 
Vol. 4, Special Issue 2, January 2017

scale. Python supports multiple programming, functional programming and procedural style. [1] [7]

\section{FLOW CHART}

As shown in flow chart our project program run as follows:

1. At the starting point program get start.

2. Linux is the operating system which is used for programming.

3. Data is accepted from various sensors.

4. Accepted data is calibrated.

5. Threshold level is detected it checks that sensed data level and calibrated data level.

6. If the calibrated value and sensed value are matched then program pointer goes to the alarm and update LCD.

7. The update LCD output again goes to the get sensor data.

8. If calibrated data and sensed data are not matched then program pointer goes directly to the update LCD.

9. Update LCD output goes to the get sensor data.

10.Stop.

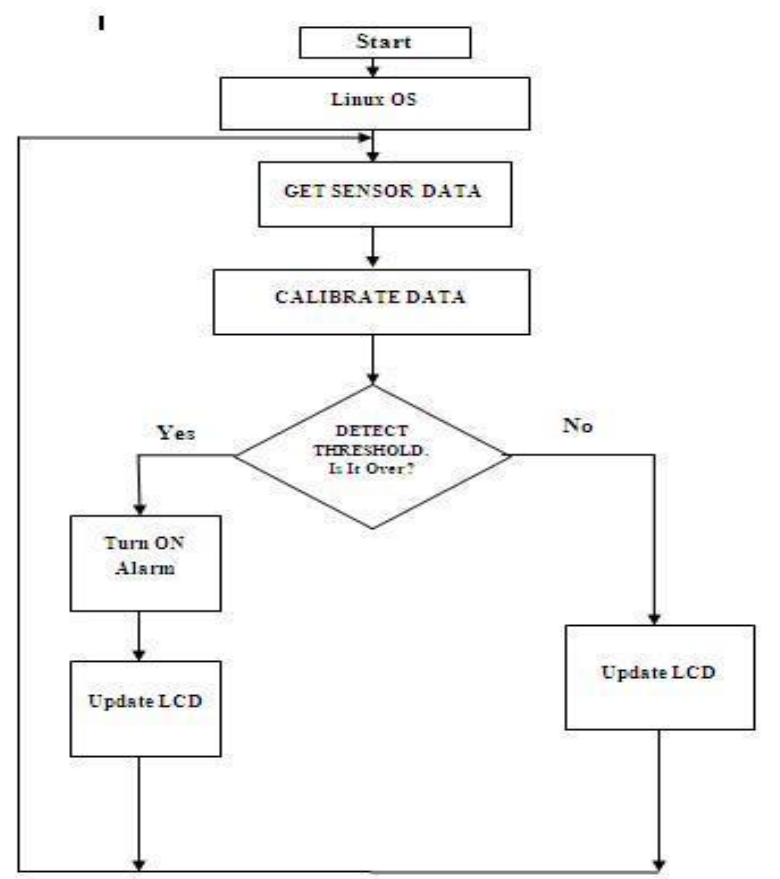

Fig 6. Flow Diagram

\section{VI.CONCLUSION}

The system is reliable to use. It is useful in any working environment sensor used are very sensitive. The accidents which are caused by ambient conditions are prevented this application can be used for all industrial area and also control various industrial parameter. It is advantageous as it offers reliability and privacy on both sides.

\section{FUTURE SCOPE}

We can use Raspberry pi model for waveform representation of data in an excel sheet. In Raspberry pi model video processor is used to display graphical as well as three dimensional view of industry.

\section{ACKNOWLEDGMENT}

We would sincerely thank to our guide Miss S.S. Kumbhar for her valuable guidance, constant assistance, support endurance and constructive suggestions for the betterment of this platform of research. We also wish to thank all the staff members of the department of E\&TC engineering for helping us directly or indirectly in completing this work successfully

\section{REFERENCES}

[1]. R. A. Ramlee, M. H. Leong and R. S. S. Singh, "Bluetooth Remote Home Automation System Using Android Application", International Journal of Engineering And Science, Volume-2, Issue 01, Pages: 149-153, 2013, ISSN: 2319 - 1813, ISBN: $2319-1805$

[2]. Sarthak Jain, AnantVaibhav, Lovely Goyal, "Raspberry Pi based Interactive Home Automation System through E-mail", International Conference on Reliability.

[3]. Raguvaran. K, Mr. J. Thiyagarajan "Raspberry PI Based Global Industrial Process Monitoring Through Wireless Communication" in International Conference on Robotics, Automation, Control and Embedded Systems - RACE 2015

[4]. www.raspberrypi.org

[5]. www.modmypi.com

[6]. www.raspberrypi.org/tutorials

[7]. www .google.com 